\title{
ENTRE A DISCIPLINA E O BIOPODER: AS NOVAS TECNOLOGIAS DE PODER NA PRODUÇÃO E ARTICULAÇÃO DAS SUBJETIVIDADES CONTEMPORÂNEAS
}

\author{
Luana de Carvalho Silva*
}

\begin{abstract}
RESUMO
Esse artigo procura discutir alguns aspectos das formas de produção de subjetividades gestadas a partir da Modernidade, através da articulação entre as normas disciplinares e o biopoder até a emergência de uma "sociedade de controle". Esse percurso teórico, vale ressaltar, é orientado pelas importantes reflexões de Michel Foucault, Giles Deleuze, Michel Hart \& Antonio Negri e, ainda, Zygmund Bauman. E apesar das diferenças e particularidades teóricas desses autores, acredita-se ser possível uma articulação teórica poderosa para tematizar como as subjetividades estão atreladas a um tipo específico de poder e, deste modo, refletir sobre a constituição do sujeito disciplinado moderno ("dócil e útil") e o sujeito marcado pela incerteza contemporânea. Tal temática é cara ao estudo jurídico, como forma de desvelar como e porquê determinados processos de fabricação de subjetividades estão atrelados às formas de poder perversas, assim, seria possível empreender a identificação das formas de poder articuladas na constituição das subjetividades e redefinir as possibilidades de subjetivação no registro da emancipação dos sujeitos, e não mais a partir da sua sujeição.

Palavras-chave: Subjetividade. Disciplina. Biopoder. Sujeição. Crise.
\end{abstract}

Sumário: 1 O SUJEITO MODERNO E "SEUS" SABERES; 2 SUBJETIVIDADE E SUJEIÇÃO; 3 A DisCIPLINA; 4 O BIOPODER E A SOCIEDADE DE CONTROLE; 5 O SUJEITO NA INCERTEZA; 6 SUBJETIVIDADES EM CRISE?; 7 CONSIDERAÇÕES FINAIS; 8 REFERÊNCIAS.

* Bacharel em Psicologia pela UFPR e em Direito pela PUC-PR, Especialista em Direito Penal e Criminologia pelo IPCC e UFPR, Mestranda no Programa de Pós-Graduação em Direito da UFPR. Endereço eletrônico: lu anacarvalho@yahoo.com.br 


\section{O SUJEITO MODERNO E "SEUS" SABERES}

A Modernidade pode ser delimitada através de diversos acontecimentos teóricos, políticos, econômicos e sociais, mas a marca do novo está representada pela emergência do sujeito como o elemento central desse período. O indivíduo apresentado como o sujeito moderno alcança um estatuto inédito, tornando-se dotado de uma razão que constrói o mundo a sua volta através do domínio da natureza e do sobrenatural. Esse sujeito aparece como senhor absoluto do mundo, centro de toda reflexão e produção possível.

Essa centralidade transporta-se para todo e qualquer tipo de conhecimento, repousando incontestavelmente no solo das ciências, das artes, da política, da economia, da filosofia, da medicina e do direito. No universo jurídico tal "soberania" fica evidente na consagrada fórmula do sujeito de direitos dotado das características fundamentais angariadas na Modernidade: a individualidade, a autonomia e a liberdade. Esse tríplice atributo do sujeito formata a noção da subjetividade moderna como abstrata e universal, destinada para toda população mundial. Mas, a subjetividade formada a partir desses atributos modernos não alcançou senão uma pequena ilha de indivíduos situados no interior do sistema econômico do capital. Assim, as promessas igualitárias e fraternais, promovidas através da centralização e valorização da racionalidade subjetiva, não realizaram seus objetivos. A razão que constrói e liberta o mundo e o homem tornou-se opressora e discriminatória.

O mundo gerado por essa racionalidade centrada no homem foi incapaz de reconhecer a humanidade daqueles que estavam além dessa razão. As guerras, a exploração desenfreada da natureza, a violência, a opressão e a desigualdade social são apenas exemplos do desencantamento desse mundo racional, que atingiu certamente a noção de sujeito.

Nesse sentido, é importante ressaltar a importância e criatividade de Michel Foucault em destacar como, no advento da Modernidade, a noção de sujeito foi requerida por uma configuração bastante especial de poder e saber. Foucault opera 
assim uma reviravolta na análise do sujeito moderno, destituindo-o dessa suposta centralidade. O núcleo central de sua obra revela que o sujeito não é dado a priori, mas é criado num período histórico definido, a partir de instrumentos sociais de controle gerenciados por um tipo especial de poder e saber.

O que o autor propõe é reconhecer através de sua "arqueo-genealogia" quais são os tipos de poder e saber que se articulam no solo da modernidade e acabam fabricando a noção de sujeito para atender os interesses econômicos gestados nesse período, rompendo em definitivo com a noção de sujeito enunciada por Kant e consagrada pelos pensadores modernos. E essa ruptura está evidente em sua crítica ao sujeito kantiano como senhor e centro da razão que define o mundo, a partir da definição do sujeito moderno como um "duplo empírico transcendental". ${ }^{1}$

Segundo Foucault, o sujeito fabricado na modernidade é duplo, porque é dotado de uma racionalidade que torna o mundo transparente ao conhecimento, um sujeito que transcende porque é dotado de uma consciência e por isso capaz de criar o mundo. Mas, existe algo no sujeito além da transcendência. O sujeito moderno também é opaco, empírico e detentor de uma materialidade incontestável. Tal duplicidade do sujeito revela a existência do jogo de poderes modernos, mascarados, de tal maneira, que é difícil reconhecer algo além do enunciado do sujeito transcendental. O mérito de Foucault está no reconhecimento da duplicidade na noção de sujeito e ao desvendar como os mecanismos de poder e opressão levaram à negação dessa materialidade do indivíduo e a valorização do aspecto transcendente.

O percurso desenvolvido por Foucault procura, assim, entender como os mecanismos de poder e saber, que estão no solo da modernidade, fabricam as subjetividades.

Foucault realiza um estudo detalhado e erudito da formação das ciências humanas como o elemento articulador do sujeito humano, através da arqueologia dos saberes. Sua tese, nesse momento, é dedicada à afirmação de que o homem nasceu de um acontecimento discursivo característico de certa episteme e, por isso, pode estar a

\footnotetext{
${ }^{1}$ FOUCAULT, M. As palavras e as coisas. São Paulo: Martins Fontes, 2002, p. 302.
} 
ponto de morrer, uma vez mudada a episteme que lhe deu origem. ${ }^{2}$ Segundo Foucault são três as epistemes: a renascentista, a clássica e a moderna.

Tais epistemes são caracterizadas por uma relação particular e inédita entre "as palavras e as coisas" que regem as regras de formação de todo conhecimento (discurso) possível em seu interior. Foucault situa o aparecimento do homem na passagem da episteme clássica para a moderna, quando é possível ao sujeito se converter em objeto para si mesmo, ou seja, quando o homem se torna sujeito e objeto do saber na constituição das ciências humanas.

Segundo Rouanet, a materialização da tese de Foucault está no enunciado do sujeito Kantiano, onde a relação do sujeito consigo mesmo se converte no fundamento último de todas as certezas, nascendo a reflexão epistemológica, no início da modernidade. ${ }^{3}$ É nesse sentido, pela primeira vez no devir discursivo, que o homem se autotematiza, possibilitando tornar-se objeto do conhecimento e fundamento de todo saber. Desse modo, o homem se transforma no sujeito das ciências humanas, no centro da racionalidade no universo da filosofia e no ator da medicina clínica. Esses, entre outros saberes, requereram a formação do sujeito sede de suas experiências discursivas, formando a noção de subjetividade como um novo cenário de saber.

É nesse quadro teórico que a idéia do sujeito como um "duplo empírico transcendental" ganha sentido, pois o homem "ocupa ao mesmo tempo a posição de um sujeito empírico no mundo, onde se encontra como objeto entre outros objetos, e a posição de um sujeito transcendental, que constitui esse mundo como o conjunto dos objetos da experiência possível". ${ }^{4}$

As ciências humanas, na Modernidade, agregaram todas as possibilidades de pensar a subjetividade em critérios de verdade, através da criação e domínio das regras discursivas. O subjetivo criado é rapidamente confiscado por esse jogo de saberes em

${ }^{2}$ ROUANET, Sergio Paulo. As razões do Iluminismo. São Paulo: Companhia das Letras, 2004, p. 174.

\footnotetext{
${ }^{3}$ Ibid., loc. cit.

${ }^{4}$ Ibid., loc. cit.
} 
formação. Os saberes do psíquico, a sociologia, a antropologia, a economia política e a biologia, são apenas alguns desses saberes modernos que se tornaram essenciais para a formação e dominação da subjetividade.

\section{SUBJETIVIDADE E SUJEIÇÃO}

Uma análise dos conteúdos discursivos dos saberes modernos permite enxergar, na formação das ciências humanas, uma centralidade no sujeito, mas é ainda incapaz de explicar como essa centralidade é possível. Além das regras de elaboração do discurso, há práticas de poder em constante movimento, que estão na fundação do solo moderno. O foco nas práticas de poder sinaliza uma mudança de rumo na obra de Foucault, pois, em um primeiro momento, o mote foucaultiano é a "exumação das regras para a formação do discurso" ${ }^{5}$ e a argumentação de que o sujeito foi requerido através da formação das ciências humanas, em um segundo momento, o mote é a "história da gênese das práticas de poder". ${ }^{6}$ Há um deslocamento da arqueologia dos saberes para a genealogia definida como "a forma de história que prescinde radicalmente da intervenção do sujeito. A genealogia é "uma forma de história que dá conta da constituição dos saberes, dos discursos, dos domínios de objetos etc., sem ter de se referir a um sujeito, seja ele transcendente com relação ao campo dos acontecimentos, seja perseguindo sua identidade vazia ao longo da história". ${ }^{7}$ Isso significa um deslocamento no conceito de subjetividade. O sujeito constituinte presente no primeiro momento é substituído pelo sujeito constituído no segundo momento. ${ }^{8}$ Segundo Rouanet, trata-se agora de mostrar "como o sujeito foi produzido

\footnotetext{
${ }^{5}$ Ibid., p. 176.

${ }^{6}$ Ibid., loc. cit.

${ }^{7}$ Ibid., loc. cit.

${ }^{8}$ Ibid., loc. cit.
} 
não por uma configuração epistêmica, mas por uma configuração de poder". ${ }^{9}$

Esses momentos, na obra de Foucault, revelam dois traços do sujeito que, antes de serem antagônicos, completam-se, fornecendo um importante passo na compreensão da dimensão adquirida pela subjetividade na Modernidade. ${ }^{10}$

Se por um lado não é possível a formação de um saber moderno que passe além da experiência do subjetivo, por outro, é necessário reconhecer a trama de poder articulada em cada episteme responsável por criar e manter a trama discursiva dos saberes e, também, do sujeito.

Cada episteme teria por fim um arranjo específico de poder. A análise foucaultiana identifica na Modernidade um tipo de poder consagrado pelas práticas disciplinares. Dessa forma, a tese foucaultiana desloca-se para a análise da economia de poder consolidada na Modernidade. Um poder com elementos específicos tramados em uma verdadeira tecnologia de produção. Essa é uma das suas principais características: o poder com uma eficácia positiva, que produz e alicia a ordem produtiva de uma sociedade capitalista. Torna-se fundamental o entendimento da tese de que o poder produz o saber e o sujeito.

A Modernidade emerge sobre uma relação de poder presente em todos os lugares e em todo o tempo. O exemplo dessa tese é a institucionalização dos hospitais gerais, das penitenciárias, das escolas, do exército, entre outros. Nessas instituições totalitárias, o exercício do poder é realizado a partir da internalização de práticas disciplinares. A vigilância incessante, a divisão celular, as técnicas de registro e exame são apenas alguns exemplos dessas práticas que, em conjunto, formam uma tecnologia de poder responsável por individualizar o homem e o constituir como um sujeito. O conjunto das informações obtidas através dessas práticas de poder disciplinar forneceu um material exaustivo de transformação, controle, domestificação e utilização dos indivíduos em prol do monopólio capitalista de produção.

É nesse sentido que as regras de subjetivação (formação de sujeitos) também

\footnotetext{
${ }^{9}$ Ibid., loc. cit.

${ }^{10}$ Ibid., loc. cit.
} 


\section{ENTRE A DISCIPLINA E O BIOPODER: AS NOVAS TECNOLOGIAS DE PODER NA}

PRODUÇÃO E ARTICULAÇÃO DAS SUBJETIVIDADES CONTEMPORÂNEAS

são as regras de sujeição. ${ }^{11}$ A subjetivação é requerida e necessária por uma tecnologia de poder disciplinar interessada em produzir "corpos dóceis e úteis" para o capitalismo. O sujeito assujeitado é a principal característica da Modernidade, pois o espaço da sujeição é a subjetividade.

Uma questão importante na obra de Foucault é a ambigüidade da noção de sujeição. Segundo Roaunet, o termo sujeição precisa ser compreendido, dentro da lógica de poder, como um processo de formação de súditos e de formação de sujeitos. $^{12}$

É nesse sentido que a temática da subjetividade é tão cara a Foucault. As práticas disciplinares promovem o assujeitamento do homem às técnicas de produção capitalista, construindo súditos na medida em que domestifica e utiliza seu corpo, mas, para promover a sujeição, é preciso criar subjetividades. E essas subjetividades estão em movimento na sociedade terminando por "necessitar" do controle disciplinar. Se o homem precisa ser domestificado e sujeitado à ordem de poder, talvez algo em sua formação escape ao controle generalizado. Seria possível pensar, então, em um espaço de resistência ao poder disciplinar, no interior da própria subjetividade.

Nessa perspectiva, é necessário reconhecer o potencial crítico no conceito de subjetividade desenvolvido por Foucault. Essa crítica convida a uma desconstrução dos conceitos de sujeito pautados na lógica transcendental (em especial, do conceito de sujeito de direitos), permitindo o reconhecimento da ambigüidade e multiplicidade das subjetividades criadas historicamente.

Através da destituição do lugar do sujeito como centro dos acontecimentos é possível vislumbrar um lugar para a subjetividade além dos poderes que a define, um lugar que conceba a produção de subjetividades em termos de libertação e não de sujeição.

${ }^{11}$ FONSECA, R. M. Modernidade e contrato de trabalho: do sujeito de direito à sujeição jurídica. São Paulo: LTr, 2002.

${ }^{12}$ ROUANET, op. cit., p. 177. 


\section{A DISCIPLINA}

Em sua leitura genealógica do poder, Foucault identificou, na passagem da Época Clássica para a Moderna, uma transformação na economia de poder, caracterizada pela substituição do poder soberano pelo poder disciplinar. ${ }^{13}$

A Época Clássica é descrita sob o signo da soberania do rei. Segundo Foucault, a soberania é caracterizada pelo imperativo de "fazer morrer ou deixar viver"14 ${ }^{14}$ os corpos que ocupavam seus territórios. O rei era o senhor absoluto da vida e da morte. O poder soberano está marcado pelo signo da negatividade, pois consome seus destinatários através da marca dolorosa no corpo. O sistema punitivo do período representava a essência desse poder, onde sobravam os horrores do suplício público responsável por expiar a culpa do indivíduo causada pela agressão ao poder real e significava o destino certo para aqueles que ousassem contestar a soberania.

O soberano centralizava toda e qualquer forma de poder. Ele era o único indivíduo, o único proprietário e podia dispor dos corpos dos súditos. Tal poder é correlato de uma sociedade agrária, fortemente marcada pela religiosidade estamental e que pouco se preocupava com a acumulação de riquezas materiais.

O advento da Modernidade foi conseqüência de uma ruptura do poder soberano e da emergência de um poder novo, a disciplina. Com essa ruptura, um novo imperativo foi enunciado: o poder agora se interessa por "fazer viver e deixar morrer". ${ }^{15}$ A vida humana tornou-se o alicerce dessa nova tecnologia de poder.

Assim, outro arranjo de poder estava sendo construído, priorizando a produção e circulação de mercadorias visando o consumo populacional, a urbanização, a propriedade privada, a industrialização e a consolidação do poder de uma nova classe social: a burguesia.

${ }^{13}$ FOUCAULT, M. Vigiar e punir. 26. ed. Petrópolis: Vozes, 2002.

${ }^{14}$ FOUCAULT, M. Em defesa da sociedade. Trad. M. E. Galvão. São Paulo: Martins Fontes, 1999, p. 286.

${ }^{15}$ Ibid., p.287. 
Mas, foi no universo do humano que essas transformações de poder fizeram-se sentir com intensidade. Na articulação dos poderes do capital, o homem ganhou uma nova e importante função econômica, passando de servo do rei a mão-de-obra na indústria capitalista. É nesse sentido que a vida humana se torna o centro de interesse do poder, por isso torna-se necessário estudá-la, dominá-la e recriá-la, de forma a atender os novos interesses econômicos e políticos em formação. A transformação dos asilos clássicos em instituições de seqüestro e educação são exemplos da estratégia criada por esse novo poder, para formatar os indivíduos. O asilo, na época medieval, foi construído em uma lógica de depósito de pessoas consideradas os "sem lugar" em uma sociedade fortemente hierarquizada. As instituições totais obedecem a uma lógica diferente, são dimensionadas como grandes fábricas de mão-de-obra, como fábricas de sujeitos perfeitamente assujeitados à nova fórmula de poder.

O modelo dessas "grandes fábricas institucionais" foi construído visando o máximo de controle e de eficiência. Daí a importância da individualização, dos registros pessoais, do controle do tempo e espaço, dos castigos normalizadores e das recompensas. Foi elaborado todo um conjunto de técnicas de adestramento sobre o corpo humano de forma a torná-lo "dócil e útil".

O modelo de produção da fábrica e seu método institucionalizado de gestão das individualidades foi transportado para outros espaços sociais, como a prisão, a escola, o exército e os hospitais. Mas, não foi apenas no universo institucional que esse modelo produziu efeitos. As técnicas disciplinares ganharam lugar em toda extensão social, modificando-se e adaptando-se a cada nova contingência ou a cada nova necessidade do poder. A arquitetura, o urbanismo, a moda, a sexualidade e a etiqueta social são exemplos da expansão dessa trama disciplinar, todavia, foi no registro do corpo humano que a disciplina consolidou sua eficácia.

Foi nesse grande espaço de controle que a idéia da subjetividade ganhou sua centralidade. A subjetividade foi possível diante das técnicas individualizantes, dos registros de informação sobre corpo, da necessidade de conhecer e dominar as paixões e as vontades do sujeito, de modo a melhorar seu desempenho laboral e aumentar sua 
impotência política. Nesse sentido, o controle, a partir da disciplina, ganhou o corpo do homem, através do adestramento da motilidade e do psiquismo.

O poder disciplinar trata-se, portanto, de um poder investido de uma concretude, pois ele constrói os sujeitos e transforma a sociedade. É um poder que está presente em todo tempo e em todo lugar do corpo social, já que ele não tem um centro ou um soberano. O poder circula através de uma rede de aparelhos sociais, institucionais e, especialmente, no próprio sujeito.

Esse é o tipo de poder identificado por Foucault, na Modernidade. É o poder que está sob a base da sociedade panóptica ${ }^{16}$ (liberal e burguesa), consagrada na formação dos Estados Nacionais, no universo jurídico, no mundo científico e tecnológico, enfim, na fórmula consagrada do sujeito individual, autônomo e capaz.

Contemporaneamente, o capitalismo industrial transmuta-se no capitalismo financeiro, inaugurando a época do mercado e globalização. A soberania do sujeito moderno dá espaço para um novo ator: as populações. Segundo Foucault, a partir das Grandes Guerras há uma nova construção de poder, mas não se trata da substituição das disciplinas e, sim, de um novo tipo de poder complementar, que se torna responsável por gerir uma sociedade em franca transformação. É a emergência do biopoder. ${ }^{17}$

A principal característica do biopoder é o deslocamento do foco do sujeito para a noção de população. O biopoder trata da gestão de técnicas de controle populacional através de questões estatísticas, de cálculo de risco e enfrentamentos territoriais. O controle se exerce a partir de gerenciamentos previdenciários, políticas públicas, questões sanitárias e da medicalização social.

A estratégia biopolítica está centrada no desenvolvimento tecnológico (biotecnologia), na velocidade na troca de informações, enfim, em uma sociedade composta pela massa e regida sob o signo do consumo.

\footnotetext{
${ }^{16}$ FOUCAULT, M. Vigiar..., op. cit.

${ }^{17}$ FOUCAULT, M. Em defesa ..., p. 289.
} 
Isso não significa que as disciplinas deixaram de existir. Na realidade, disciplina e biopoder formam um complexo assentado na contemporaneidade. Nesse sentido, as subjetividades não deixaram de ser o foco do poder em relação às populações. As estratégias de poder estão em transformação na sociedade e, assim, também estão as subjetividades.

\section{O BIOPODER E A SOCIEDADE DE CONTROLE}

Na sociedade contemporânea pode-se identificar um deslocamento no registro de poder, que assume a forma do biopoder.

O biopoder é delineado como um novo tipo de tecnologia de poder, inicialmente integrado ao poder disciplinar, mas com instrumentos diferentes deste. Segundo Prata, essa nova técnica de poder não se aplicava ao "homem corpo", mas ao "homem ser vivo", ao "homem espécie". Nesse sentido: "Enquanto a disciplina tentava reger a multiplicidade dos homens - vigiados, treinados e punidos -, a biopolítica se dirigia à multiplicidade dos homens, uma vez que estes constituíam um grupo afetado por processos próprios à vida, como o nascimento, a morte, a produção e a doença". ${ }^{18}$

Assim, na sociedade biopolítica, o sujeito não é mais considerado a partir dos detalhes próprios do seu corpo. A individuação progressiva do corpo, através das técnicas disciplinares, cede lugar aos mecanismos de regulação em escala global. O sujeito perde sua centralidade como destino do poder e, agora, é descrito em termos de padrões e escalas populacionais. A biopolítica não se destina tão-somente à domestificação e utilização dos corpos, mas à obtenção de estados de regularidade e

${ }^{18}$ PRATA, Maria Regina. Da norma disciplinar à iniciativa: os processos e os parâmetros normativos contemporâneos. In: PEIXOTO JUNIOR, C. A. [org.] Formas de subjetivação. Rio de Janeiro: Contra Capa, 2004. p. 50. 
equilíbrio globais. ${ }^{19} \mathrm{O}$ molde desenvolvido pela sociedade disciplinar para fabricar as individualidades necessárias para a produção capitalista é substituído por um modelo de modulação e de regulamentação, em que a subjetividade individualizada dá lugar a uma subjetividade produzida em série. É a passagem da era industrial para a era empresarial.

Segundo Prata: "Após uma primeira tomada do poder sobre o corpo, pelo poder disciplinar, haveria uma segunda tomada não individualizante, mas massificante. A biopolítica lidaria com fatores permanentes de subtração das forças humanas, como a diminuição do tempo de trabalho, a baixa de energia e os custos econômicos". ${ }^{20}$

A sociedade biopolítica está inscrita no signo de um capitalismo financeiro e intelectual responsável por fornecer as possibilidades de um mundo globalizado e virtual regido pela tecnociência. Nesse novo mundo, as fronteiras territoriais são diluídas em uma grande "rede" mundial conectada 24 horas. Os limites temporais e espaciais são facilmente ultrapassados por uma tecnologia de informação sem centro. O capital é dotado de intensa fluidez, através das transferências financeiras informatizadas e da velocidade das transações comerciais realizadas no mercado de ações e, nesse sentido, a sociedade e o sujeito também passam por uma intensa redefinição, a partir da nova lógica de consumo. Um outro ponto importante é a reconstrução das instituições sociais na lógica biopolítica.

Segundo Deleuze, a atual sociedade biopolítica pode e deve ser inscrita no registro da sociedade de controle. ${ }^{21}$ Isso significa compreender, contemporaneamente, a passagem da sociedade disciplinar para a sociedade de controle e como "o espaço estriado das instituições da sociedade disciplinar dá lugar ao espaço liso da sociedade de controle". ${ }^{22}$

\footnotetext{
${ }^{19}$ Ibid., loc. cit.

${ }^{20}$ Ibid., p. 50.

${ }^{21}$ O termo "sociedade de controle" é emprestado por Deleuze do "mundo paranóico de
} William Burroughs". (HART, Michael. A sociedade mundial de controle. In: ALLIEZ, E. [Org.]. Gilles Deleuze: uma vida filosófica. Trad. Ana Lucia de Oliveira. Rio de Janeiro: 34, [s.d.]. p. 357).

${ }^{22}$ Ibid., loc. cit. 
Essa "passagem" vislumbra um desmoronamento dos muros que definem as instituições, pois o modelo institucional da sociedade disciplinar caracterizado pelo confinamento e seqüestro dos sujeitos em instituições como a prisão, o hospital, a fábrica, a escola e a família encontram-se em uma crise estrutural. A Modernidade disciplinar foi construída segundo um modelo delimitador, marcando fortemente os limites discursivos entre um ou outro campo de saber e poder. Assim, a função das instituições é delimitar e separar quem está dentro dela daqueles que estão "fora", institucionalizando e moldando o sujeito, conforme as regras disciplinares. O jogo discursivo entre o "dentro" (que pertence ao molde) e o "fora" (que não pertence ao molde), atravessa todas as possibilidades de existência como regra de verdade na sociedade. Em última instância, essa é a função do poder normalizador: estabelecer os limites entre o que está dentro e fora, como os pares: "normal/anormal", "criminoso/não criminoso", "doente/saudável", "educado/não-educado", "louco/nãolouco".

A emergência do "controle" implica em consideráveis modificações em todos os níveis da sociedade. O desmoronamento institucional promovido pelo "controle" pode ser sentido na substituição da fábrica pela empresa, da escola pela formação permanente, do exame pelo controle contínuo. Trata-se, efetivamente, de pensar as relações de poder e saber sob outras regras. Essas regras já não são mais encontradas nos limites normalizantes que formavam um "poder estriado".

Segundo Hart, na sociedade de controle há cada vez menos distinções entre o dentro e o fora, formando um "elemento de mudança geral na maneira pela qual o poder marca o espaço". ${ }^{23}$ A soberania moderna, concebida em termos da formação de Estados Nacionais, dá lugar a Estados artificiais, virtuais, onde a credibilidade de seus títulos financeiros é mais visível que seu território. Ainda, "a dialética moderna do fora e do dentro foi substituída por um jogo de graus e intensidades, hibridismo, e artificialidade". ${ }^{24}$

\footnotetext{
${ }^{23}$ Ibid., p. 358.

${ }^{24}$ Ibid., loc. cit.
} 
Os limites definidos em pares, pela disciplina, são colocados em cheque pela multiplicidade da biopolítica, acabando por formar uma sociedade sem muitos lugares marcados, acentuando o "declínio do fora". Na sociedade de controle, todos são considerados "dentro" dos artifícios gestados pelo biopoder, formando um imenso espaço "liso", substituindo o controle através da individuação, pelo controle a partir da massificação.

O poder na sociedade de controle pode ser definido:

O poder agora é exercido mediante máquinas que organizam diretamente o cérebro (em sistemas de comunicação, redes de informação etc.) e os corpos (em sistemas de bem-estar, atividades monitoradas etc.) no objeto de um estado de alienação independente do sentido da vida e do desejo de criatividade. A sociedade de controle pode, dessa forma, ser caracterizada por uma intensificação e uma síntese dos aparelhos de normalização de disciplinariedade que animam internamente nossas práticas diárias e comuns, mas, em contraste com a disciplina, esse controle estende bem para fora os locais estruturados de instituições sociais mediante redes flexíveis e flutuantes. ${ }^{25}$

O declínio do "fora", realizado pela sociedade de controle, acaba por dissolver os limites institucionais que formam as subjetividades, provocando intensas transformações no universo do sujeito. O impacto dessas transformações na subjetividade e suas implicações são os objetos de estudo da seqüência deste artigo.

\section{O SUJEITO NA INCERTEZA}

Até esse momento visualizou-se como as instituições disciplinares realizaram, de forma determinante, as possibilidades do poder disciplinar se exercer sobre os sujeitos, e mais, discutiu-se o deslocamento desse poder contemporaneamente e algumas das transformações sociais operadas entre a "sociedade disciplinar" e a "sociedade de controle". Colocando em foco o singelo objetivo desse artigo, resta

\footnotetext{
${ }^{25}$ NEGRI, R.; HART, M. Império. Rio de Janeiro: Record, 2001, p. 42-43.
} 
avaliar os efeitos desse deslocamento na constituição das subjetividades atuais.

Nesse sentido, Zygmunt Bauman fornece um instrumento teórico poderoso para a compreensão das formas de produção de subjetividades contemporâneas. Para o autor é preciso não se conformar com a situação do homem no mundo neoliberal, e sim, buscar um meio de assegurar ou garantir espaços de "liberdade individual", frente às peripécias do consumo. Disposto a encontrar soluções para esta questão, o autor resgata a categoria do político como forma de valorizar as experiências coletivas dos sujeitos humanos e, assim, garantir a possibilidade de liberdade. ${ }^{26}$ As soluções delineadas por Bauman, por si só, representam um objeto de pesquisa, entretanto, para os objetivos desse artigo interessa sua poderosa descrição dos sujeitos que vivem no mundo neoliberal, na globalização, na sociedade de consumo, magistralmente retratados em sua obra.

O mundo moderno de Bauman é descrito na ordem da Sicherheit, ${ }^{27}$ ou seja, nos registros da certeza, segurança e garantia. Essas são as condições de possibilidade para a vida do homem no mundo. São também as promessas civilizatórias que levariam os homens a ingressarem no mundo social, abandonando a supremacia dos desejos individuais. A certeza, a segurança e a garantia são "os três ingredientes de Sicherheit como as condições para a autoconfiança de que depende a capacidade de pensar e agir racionalmente". ${ }^{28}$ Todavia, a sociedade de "consumo" contemporânea, delineada com as experiências neoliberais, fundamenta-se em outro registro. Este registro é visualizado na crescente flexibilização das relações institucionais que ligam os sujeitos (como a flexibilização dos direitos trabalhistas), a fluidez do capital financeiro internacional e sua desterritorialização, o enfraquecimento dos Estados como centros de decisão e controle político frente à impessoalidade do mercado de consumo internacional, enfim, pelo declínio das formas coletivas de participação dos indivíduos.

\footnotetext{
${ }^{26}$ BAUMAN, Zygmund. Em busca da política. Rio de Janeiro: Zahar, 1999, p. 15.

${ }^{27}$ Ibid., loc. cit.

${ }^{28}$ Ibid., p. 25.
} 
Neste registro, Bauman define o sujeito contemporâneo como um "homem modulado", ${ }^{29}$ isso significa que as atuais subjetividades não mais se inscrevem em um perfil ou uma função definitivos delineados no interior de instituições determinadas. Observa-se, contemporaneamente, o surgimento de um tipo de homem que não tem "formato certo predeterminado, mas um conjunto infinito de formas e expansões possíveis". Assim, o "homem modulado" não pode e nem deve ser determinado finitamente, pois é um sujeito que adquire "qualidades móveis, disponíveis e cambiáveis", diante de um mundo de infinitas possibilidades onde os laços institucionais que os homens e as mulheres se ligam uns aos outros são construídos ad hoc.

Os homens e mulheres modulados são constituídos sem um código rígido de regras, mas são instruídos a uma enorme capacidade de flexibilização das condições ou padrões socializados. Enfim, são sujeitos apresentados a múltiplas possibilidades de escolha, incluindo suas formas de subjetivação. Essas escolhas já não possuem um caráter rígido ou de vinculação institucional, pois cada uma delas recai exclusivamente sobre o sujeito, sendo sua responsabilidade. Os sujeitos modulados não podem dividir essa responsabilidade com o universo institucional, tampouco coletivamente. É neste sentido que o homem modulado também é "automodulante", pois se os sujeitos possuem tantas possibilidades de escolha e são "livres" para decidi-las conforme suas vontades, eles também são única e exclusivamente responsáveis por elas, dito de outra forma, se existem tantas escolhas a ser perseguidas, o sujeito tem a obrigação de realizar a pretendida. Daí a consolidação de um aspecto menos atraente da "modulação", que envolve a formação de riscos e incertezas inerentes a toda escolha.

Os homens modulados são os produtos típicos da "sociedade multirrede", reitora da formas de consumo liberalizante, tecnológico e mercadológico. As novas subjetividades em formação são fundadas na cultura da imediatialismo, da possibilidade da obtenção do prazer contínuo e de uma temporalidade instantânea. É a cultura do "aqui e agora" que liga a promessa de um estado de bem-estar eufórico, em

${ }^{29}$ Segundo BAUMAN, o termo "homem modulado" foi originalmente descrito por Ernest Gellner. (op. cit., p. 160). 


\section{ENTRE A DISCIPLINA E O BIOPODER: AS NOVAS TECNOLOGIAS DE PODER NA}

PRODUÇÃO E ARTICULAÇÃO DAS SUBJETIVIDADES CONTEMPORÂNEAS

que não é permitido sentir-se triste ou angustiado. E para esses "pecados" contemporâneos há ainda a garantia da medicalização, das "pílulas de felicidade", que oferecem a tentadora possibilidade de recusa à dor e, de quebra, de regresso ao consumo. Esta é a lógica dessa sociedade: é possível ter acesso a qualquer escolha, desde que seja no interior do consumo.

A liberdade dos sujeitos encontra aí seu referencial. As múltiplas ofertas apresentadas aos sujeitos, pelo mercado, refletem a impressão de maior liberdade. De fato, em nenhum outro momento fomos apresentados a tantas possibilidades de escolha (de "produtos, bens e serviços"), mas tal liberdade "sem limites" encontra uma clara moldura: a integração e capacidade de consumo. Segundo Bauman, é nesse sentido que a liberdade, atualmente, foi "privatizada", pois ela deixou de se realizar em um espaço coletivo de discussão e debate (um espaço político) para tornar-se um atributo do mercado destinado aos sujeitos.

Entretanto, existem outros aspectos menos glamourosos nessas novas subjetividades. Nesse aspecto, como se apresentam as formas de controle?

Os sujeitos livres para o consumo estão, segundo Bauman, imersos em um "caldeirão de Unsicherheit". Se a modernidade disciplinar estava sob o signo da Sicherheit (certeza, segurança e garantia), hoje vive-se cercado pelas incertezas, inseguranças e falta de garantias oriundas de todos os lugares e de todas as relações da sociedade. A Unsicherheit (incerteza, insegurança e falta de garantia) é o que possibilita a construção dos sujeitos modulados, os atores da sociedade de consumo.

Um mundo capaz de oferecer múltiplas escolhas não fornece a garantia de acerto, de solução e de certeza. Esse é o aspecto trágico da liberdade privatizada, a Unsicherheit é responsável por criar e manter a eterna insatisfação do sujeito necessária para a preservação do mercado de oferta de "bens, produtos e serviços". Deste modo, o controle perde pouco a pouco o caráter de disciplina para o trabalho, caminhando para a incerteza generalizada sobre vida. 


\section{SUBJETIVIDADES EM CRISE?}

Se os processos de subjetivação são constituídos historicamente e tramados por uma configuração especial de saber e poder gestadas em um período histórico, assim também é a própria noção de subjetividade derivada "do modo como as práticas de poder e de saber se esforçam para aderir às formas de subjetivação, no sentido de adestrá-las e submetê-las aos seus próprios interesses". ${ }^{30}$

As disciplinas características da Modernidade investiram uma enorme quantidade de energia em processos de subjetivação que visavam individuação do corpo e a constituição de uma subjetividade "dócil e útil" para sua economia de poder. A conseqüência desse processo é a criação de um sujeito universal, soberano e fundamento último de todas as certezas e verdades.

Segundo Prata, o sujeito na Modernidade passava:

Linearmente pelas várias instituições (da família à escola, da escola ao quartel, do quartel à fábrica), sendo por elas formado. Cada instituição tinha suas próprias regras e lógicas de subjetivação, o que protegia o indivíduo, ao menos parcialmente, contra a força das outras instituições. Os territórios eram bem definidos, havia uma clara distinção entre o interior e o exterior institucional e a função que cabia a cada instituição. ${ }^{31}$

Todavia, o impacto transformador imposto pela sociedade de controle promoveu o descentramento do sujeito. O lugar central ocupado pelo sujeito disciplinado como palco de todo investimento de poder vai, pouco a pouco, sendo substituído. Isso não significa que o sujeito deixa de existir, mas na sociedade de controle são formados novos processos de subjetivação, que acabam abrindo espaço para a constituição de novas formas de subjetividades.

A aclamada "crise do sujeito" encontra, nas reflexões de Foucault, um percurso diferente. Foucault mostra que o que está em crise é um modelo de

\footnotetext{
${ }^{30}$ PRATA, op. cit., p. 49.

${ }^{31}$ Ibid., loc. cit.
} 
subjetividade formado pelas práticas disciplinares, e tal crise é correlata da articulação de uma nova economia de poder, da passagem da disciplina para a biopolítica. Os processos de subjetivação disciplinares dão lugar aos processos de subjetivação biopolíticos característicos de uma sociedade de controle. Segundo Hart e Negri, o significado da "crise" das instituições disciplinares é definido: "A crise significa, em outras palavras, que hoje os cercados que costumavam definir o espaço limitado das instituições foram derrubados, de modo que a lógica que funcionava principalmente dentro das paredes institucionais agora se espalha por todo terreno social. Interior e exterior estão se tornando impossíveis de distinguir". ${ }^{32}$

Tal crise dos parâmetros institucionais modernos provocou intensas transformações no universo dos indivíduos, uma vez que atingiram justamente os processos de subjetivação consagrados pela dinâmica de poder disciplinar.

Na sociedade de controle, os processos de subjetivação não estão relacionados com alguma prática disciplinar e passam pouco pelo controle institucional. Desse modo, o sujeito foi destituído das antigas referências que moldavam os processos subjetivos. A linearidade dos processos de subjetivação moderna foi substituída por uma multiplicidade de fatores que integram a subjetividade.

Nesse mundo do controle, a herança transcendental do sujeito universal, capaz de ser o centro das certezas e verdades do mundo é negada. Em seu lugar, surge um sujeito híbrido marcado pela inexpressão, sem lugar no mundo, mas presente em todos os lugares ao mesmo tempo. Esse novo sujeito deixa seu lugar soberano e não encontra nenhum lugar possível definido, agora pertencendo à aldeia global.

O sujeito contemporâneo não encontra limites institucionais ou regras de verdade estabelecidas. Também não é mais individuado ou domestificado. Esse novo sujeito foi descrito por Bauman como o sujeito das incertezas e da insegurança em relação ao mundo e a si mesmo. ${ }^{33}$ É o sujeito de uma sociedade que a regra de socialização caminha para a lógica de consumo desenfreado, onde a mídia aparece

\footnotetext{
${ }^{32}$ NEGRI; HART, op. cit., p. 216.

${ }^{33}$ BAUMAN, op. cit.
} 
como um espaço possível de acolhimento frente ao desamparo institucional, mas tal fato é somente uma promessa impossível, pois a nova lógica de poder promove justamente o fim das certezas, das verdades absolutas, enfim, da centralidade do sujeito.

As novas subjetividades são assim apresentadas: o depressivo no lugar do louco, o colaborador no lugar do operário e ainda o criminoso, que deixa de ser um "anormal" para se tornar o "inimigo social comum".

\section{CONSIDERAÇÕES FINAIS}

O impacto das transformações nas relações de poder é imenso na formação das subjetividades. Na sociedade atual, o aumento da miséria e o enfraquecimento dos vínculos institucionais promovem uma intensificação da sensação de abandono, de incapacidade e sujeição dos sujeitos. Nesse sentido, as subjetividades formadas pela gestão biopolítica dos corpos chamam atenção pela pobreza dos processos de subjetivação que pouco desenvolvem os registros da linguagem e do pensamento. $\mathrm{O}$ sujeito só tem valor quando pensado "em larga escala", desvalorizando as experiências individuais.

Todavia, tais reflexões não significam uma apologia à forma de subjetivação disciplinar. O que interessa destacar é como as formas de subjetivação são produzidas historicamente, a partir de relações de poder e saber. As diferenças entre as subjetividades produzidas pela disciplina e o biopoder sinalizam uma mudança nos processos de subjetivação gestados.

Pensar as formas de produção das subjetividades é zelar pela experiência do novo, na medida em que não é mais possível ter na soberania do sujeito a referência para os processos de subjetivação e não se deve aceitar a incerteza e a insegurança como resposta. 


\section{REFERÊNCIAS}

BAUMAN, Zygmund. Em busca da política. Rio de Janeiro: Zahar, 1999.

DELEUZE, Gilles. Conversações. Rio de Janeiro: 34, 1992.

FONSECA, R. M. Modernidade e contrato de trabalho: do sujeito de direito à sujeição jurídica. São Paulo: LTr, 2002.

FOUCAULT, Michel. A história da sexualidade. 14. ed. Rio de Janeiro: Graal, 2003. t. 1: A vontade de saber.

. As palavras e as coisas. São Paulo: Martins Fontes, 2002.

. A verdade e as formas jurídicas. 3. ed. Rio de Janeiro: Nau, 2003.

- Ditos e escritos: a problematização do sujeito: psicologia, psiquiatria e psicanálise. Rio de Janeiro: Forense, 2002. v. 1.

Em defesa da sociedade. Trad. M. E. Galvão. São Paulo: Martins Fontes, 1999.

. Microfísica do poder. Trad. R. Machado. 2. ed. Rio de Janeiro: Graal, 1979.

. Vigiar e punir. 26. ed. Petrópolis: Vozes, 2002.

FREUD, Sigmund. O mal estar da civilização. (1929). Edição Standart das Obras Completas de Sigmund Freud. Rio de Janeiro: Imago, 1996. v. 21.

HART, Michael. A sociedade mundial de controle. In: ALLIEZ, E. [org.]. Gilles Deleuze: uma vida filosófica. Trad. Ana Lucia de Oliveira. Rio de Janeiro: 34, [s.d.]. p. 357-372.

NEGRI, R.; HART, M. Império. Rio de Janeiro: Record, 2001.

PRATA, Maria Regina. Da norma disciplinar à iniciativa: os processos e os parâmetros normativos contemporâneos. In: PEIXOTO JUNIOR, C. A. [org.]. Formas de subjetivação. Rio de Janeiro: Contra Capa, 2004. p. 37-68.

ROUANET, Sergio Paulo. As razões do Iluminismo. São Paulo: Companhia das Letras, 2004. 